\title{
The Relationship between Vascular Endothelial Growth Factor A (VEGFA) Gene Polymorphism and Pre-Eclampsia in Egyptian Pregnant Women
}

\author{
Sobhy Hassab El-Nabi ${ }^{1}$, Islam El-Garawani ${ }^{1 *}$, Ayman Elsayed ${ }^{1}$, Heba Salama ${ }^{2}$ \\ ${ }^{1}$ Department of Zoology, Faculty of Science, Menoufia University, Egypt \\ ${ }^{2}$ Department of Obstetrics and Gynecology, Faculty of Medicine, Menoufia University, Egypt
}

DOI: $10.36348 /$ sijog.2020.v03i06.004

| Received: 10.06.2020 | Accepted: 18.06.2020 | Published: 30.06.2020

*Corresponding author: Islam El-Garawani

\section{Abstract}

Pre-eclampsia (PE) is a complicated heterogeneous disorder associated with an increased risk of maternal death. There is a major variation in the literature about the genetics of pre-eclampsia (PE). This study aims to estimate the association between Vascular Endothelial Growth Factor A (VEGFA) gene single nucleotide polymorphism (rs1570360) and the development of PE in the Egyptian population. Genotyping was performed using the tetra-primer amplificationrefractory mutation system (ARMS-PCR) and the results were confirmed by the PCR-RFLP method in 100 patients with PE and 100 PE-free patients. Results revealed that GG (wild type) genotype of rs 1570360 was identified in 100 patients, (42\%) of them had pre-eclampsia. SNP genotype AA was found in 84 patients and (42\%) of them had pre-eclampsia. The frequency of AG genotypes was significantly low (16\%). However, the odds ratio was 40.37 for homozygocity and 9.5 for heterozygous alleles. Our study concluded that the AA and AG genotypes were not associated with PE. There is a significant relationship between the AA allele polymorphism and the severity of PE.

Keywords: Pre-eclampsia, Vascular Endothelial Growth Factor A (VEGFA), Single nucleotide polymorphisms.

Copyright @ 2020: This is an open-access article distributed under the terms of the Creative Commons Attribution license which permits unrestricted use, distribution, and reproduction in any medium for non-commercial use (NonCommercial, or CC-BY-NC) provided the original author and source are credited.

\section{INTRODUCTION}

Pre-eclampsia is a medical disorder that occur in the second half of pregnancy including the development of new-onset hypertension, new-onset proteinuria and linked with many other symptoms, including headaches, visual disturbances, epigastric pain and the rapid oedema development. Diagnostic criteria include the development of hypertension, defined as persistent systolic blood pressure (BP) of $140 \mathrm{~mm} \mathrm{Hg}$ or higher, or a diastolic BP of $90 \mathrm{~mm} \mathrm{Hg}$ or higher after 20 weeks of gestation in women with previously normal blood pressure [1,2]. The occurrence in non-hypertensive pregnant women is four to five times [3]. Pre-eclampsia may worsen all other hypertensive disorders. Although the evidence from renal biopsy studies suggest that the diagnosis of superimposed pre-eclampsia may be often erroneous [4]. The probability of pre-eclampsia is double to four times greater if a patient has a first-degree relative with a history of the disorder and is sevenfold greater if a previous pregnancy was pre-eclampsia-complicated [5, $6]$. Severe pre-eclampsia can induce acute as well as long-term complications for both the woman and her child. The maternal complications may be stroke, pulmonary oedema, myocardial infarction, acute respiratory distress syndrome, coagulopathy, severe renal failure and retinal injury. Such conditions are more likely to occur in the presence of pre-existing medical conditions and with severe pre-eclampsiarelated maternal organ dysfunction. Fetal and new-born complications of severe pre-eclampsia result from exposure to uteroplacental insufficiency or from preterm birth, or both [7-9]. In recent years, significant steps have been taken for the prediction of many diseases and to their response to the specific medications throughout the incidence of certain gene polymorphisms $[10,11]$.

\section{PATIENTS AND METHODS}

The study population consisted of 200 patients who were divided equally into two groups. The first 
consisted of patients with pre-eclampsia, and the second was the pre-eclampsia-free patients. All participants were genotyped for the VEGFA gene, rs1570360.The study plan was reviewed and approved by the Ethical Committee at the Faculty of Medicine, Menoufia University (No: 5/2020OBSGN3). Patients were enrolled from the Department of Obstetrics and Gynecology, Menoufia University Hospital, Egypt.

\section{Samples Collection and clinical investigations}

The venous peripheral blood samples were obtained using sterile tubes containing K2-EDTA (KEMICO vacutainer, Egypt). All samples were labeled by numbers $(\mathrm{N})$ that matched the number of other investigations. Clinical evaluation of the patients, including complete history taking (age, parity and gravidity), associated medical disorders and PE in previous pregnancies. Moreover, the measurement of blood pressure (BP), body mass index (BMI) and presence of oedema were done. Biochemical laboratory assessments such as complete blood count (CBC), Alanine aminotransferase (ALT), aspartate aminotransferase (AST), albumin, prothrombin time and creatinine were investigated by using other coagulated sample serum aliquots. Albumin level by urine dipstick also was done and the results were expressed in (+) mark.

\section{Isolation of Peripheral Blood Leucocytes}

About $1.5 \mathrm{~mL}$ of venous blood samples were incubated with five volumes of erythrocyte lysing buffer $\left(0.015 \mathrm{M} \mathrm{NH} \mathrm{NH}_{4} \mathrm{C}, 1 \mathrm{mM} \mathrm{NaHCO}_{3}, 0.1 \mathrm{mM}\right.$ EDTA). Samples were centrifuged for $5 \mathrm{~min}$ at 1200 rpm using cooling centrifuge (Sigma 3K30, Germany). These steps were repeated until the appearance of a white leucocytes pellet [12].

\section{Total genomic DNA isolation}

Genomic DNA was isolated from the peripheral blood leukocytes according to the salting-out extraction method [13]. Polymerase chain reaction (PCR) products were directly stained with ethidium bromide and then loaded into the $1.5 \%$ agarose gel [14].

\section{Genotyping}

The tetra primers amplification-refractory mutation system (ARMS-PCR) and confirmation by PCR-restriction fragment length polymorphism (RFLPPCR) method were carried out to investigate the SNP (rs1570360) polymorphisms in the VEGFA gene. All amplifications were performed in a thermocycler Master cycler gradient (Eppendorf, Germany). DNA samples were processed for initial denaturation at $94^{\circ} \mathrm{C}$ for $10 \mathrm{~min}$, followed by 35 cycles of denaturation at $94^{\circ} \mathrm{C}$, annealing at $55^{\circ} \mathrm{C}$ and extension at $72^{\circ} \mathrm{C}$ for 1 min each. For ARMS-PCR, the oligonucleotide primers were 5' CAGGGGTCACTCCAGGATTCCAA -3' (Outer forward), 5' CAAGTGGGGAATGGCAAGCAAA $\quad-3^{\prime} \quad$ (Outer reverse), 5' GCCCGAGCCGCGTGTGTAA 3' (Inner forward) and 5 GACAGGCGAGCCTCAGCACC 3 (Inner reverse).

The amplification reactions were carried out using the four primers in one reaction tube at the same time and the amplicons were 684, 379 (A allele) and 344 ( $\mathrm{G}$ allele) base pairs.

For RFLP-PCR, the oligonucleotide primers 5' CAGGGGTCACTCCAGGATTCCAA 3' (Outer forward), 5' CAAGTGGGGAATGGCAAGCAAA 3' (Outer reverse), were used. The procedure of the restriction enzyme digestion consisted of $10 \mu \mathrm{L}$ of PCR reaction mixture, $18 \mu \mathrm{L}$ of nuclease-free water, $2 \mu \mathrm{L}$ $10 \times$ Buffer $\mathrm{R}$ and $2 \mu \mathrm{L}$ of MnII restriction endonuclease (Thermo Scientific, US) at $37{ }^{\circ} \mathrm{C}$ for $2 \mathrm{~h}$. MnII digestion of allele GG yields fragments of 426 and 258 base pairs, whereas DNA containing the allele AA yields fragments of 684 base pairs. The fragments of heterozygous alleles (GA) appeared at 684, 426, 258 and base pairs. The Restriction digestion products were separated on $2.5 \%$ agarose gels (Sigma-Aldrich, Germany) and stained with ethidium bromide for visualization on a UV transilluminator.

\section{Statistical Analysis}

Data were collected, tabulated and statistically analyzed by an IBM compatible personal computer with SPSS statistical package version 23 (SPSS Inc. Released 2015. IBM SPSS statistics for windows, version 23.0, Armnok, NY: IBM Corp). Two types of statistical analysis were done; Descriptive statistics, the quantitative data was represented in the form of mean $\left(\mathrm{X}^{-}\right)$, standard deviation (SD), range and qualitative data was represented in the form numbers $(\mathrm{N})$ and percentages $(\%)$. While the analytic statistics, including Chi square test $\left(\chi^{2}\right)$, was used to study the association between two qualitative variables. $P$ value of $\leq 0.05$ was considered statistically significant.

\section{RESULTS}

\section{Clinical evaluation of the pre-eclampsia cases} $(\mathbf{n}=\mathbf{1 0 0})$

- The number of cases diagnosed with PE was 100 participants, most of them were $28.2 \pm 5.83$ years old. The Systolic blood pressure (BP) was $157 \pm 19.5$ while the Diastolic BP was $100.6 \pm 11.96$.

- Most of cases according to their Gravidity were gravid a $3(\mathrm{G} 3)$ about $32 \%$ then gravid a $1(\mathrm{G} 1)$ by $24 \%$, G2 (22\%), G4 (12\%), primi gravid a (PG) $8 \%$ and the last one was G5 $2 \%$.

\section{Clinical evaluation of control group $(n=100)$}

- The number of control cases was 100 women with mean age 27 years $(27.5 \pm 5.82)$, Systolic BP was within normal range $(115 \pm 5.03)$ and Diastolic BP was less than $95 \mathrm{~mm} \mathrm{Hg}$ $(95 \pm 5.03)$.

- According to gravidity of the participants: PG 
was 8 women ( $8 \%)$, G1 was 20 women $(20 \%)$, G2 was 30 women (30\%), G3 was 32 women (32\%), G4 was 8 women (8\%) and the last one was G5 was 2 women ( $2 \%)$.

- Normal cases have no protein detected in urine and normal range of laboratory kidney and liver functions were recorded.

- They had no history of medical disorders or previous history of PE in previous pregnancy.

Evaluation of liver functions, kidney functions and proteinuria in cases with pre-eclampsia

- The protein in urine was measured with urine dipstick and most cases showed protein in urine $(+)$ in $(36 \%)$, participant; $(+++)$ in $26 \%$ of the cases; $(++++)$ in $16 \% ;(++)$ in $14 \%$ and Traces in 8 cases $(8 \%)$.

- Liver enzymes were normal in 90 cases $(90 \%)$ and Higher than normal range in $10 \%$.

- Creatinine level was normal in 88 women $(88 \%)$, low in $10 \%$ and high in $2 \%$.

Severity of complications and previous history in the pre-eclampsia cases $(\mathbf{n}=100)$

- According to the BP, degree of protein in urine and the laboratory investigations, the $100 \mathrm{PE}$ women were diagnosed as mild PE (54\%) and $46 \%$ were severe.

- Complications: There were No Complications in 72 cases $(72 \%)$, Fits (Eclampsia) were in 8 women $(8 \%)$, Preterm labor was in $8(8 \%)$, IUFD was in 4 cases (4\%), eclampsia and IUFD were 2 cases (2\%), Renal affection \& dialysis (HELP) were in 4 cases $(4 \%)$ and Oligohydraminos was in 2 cases (2\%).

- The history of PE in previous pregnancy was not recorded in 90 women $(90 \%)$ but the previous history was present in 6 cases $(6 \%)$, SLE in 2 cases which was diagnosed as medical disorder associated with pregnancy (2\%), and CHTN in 2 cases $(2 \%)$ as they had hypertension disease before pregnancy.

\section{Genotyping of rs1570360}

Table-1 shows that there was no association of rs1570360 with the PE. The GG (wild type) genotype of rs1570360 was identified in 90 patients, 42 of them had pre-eclampsia. SNP genotype AA was found in 84 patients and 42 of them had pre-eclampsia. There is no statistical significance between the occurance of preeclampsia and the mutant homo/heterozygous allellic forms of the rs 1570360 SNP.

Table-1: Genotyping of control and pre-eclampsia cases

\begin{tabular}{|c|c|c|c|c|c|}
\hline Genotyping & $\begin{array}{c}\text { Cases (PE) } \\
(\mathrm{n}=100) \\
\mathrm{N}(\%)\end{array}$ & $\begin{array}{c}\text { Control } \\
(\mathrm{n}=100) \\
\mathrm{N}(\%)\end{array}$ & $\begin{array}{c}\text { Total } \\
(\mathrm{n}=200) \\
\mathrm{N}(\%)\end{array}$ & $\begin{array}{c}\text { Test of significance } \\
\left(\chi^{2}\right)\end{array}$ & $P$ value \\
\hline GG & $42(42)$ & $48(48)$ & $90(45)$ & \multirow{3}{*}{1.785} & \multirow{3}{*}{0.41} \\
\hline $\mathbf{A A}$ & $42(42)$ & $42(42)$ & $84(42)$ & & \\
\hline AG & $16(16)$ & $10(10)$ & $26(13)$ & & \\
\hline
\end{tabular}

Table-2 shows that there is a significant $(P$ $\leq 0.001$ ) association between the mutant allele (homo/heterozygous) and the severity of pre-eclampsia. Results revealed a strong relationship between AA and severe cases, whereas, AA was found in $73.9 \%$, GG $(8.7 \%)$ and $A G(17.4 \%)$. However, the odds ratio was
40.37 for homozygocity (AA) and 9.5 for the AG heterozygous allele (Table-3). The polymorphism homozygocity (AA) was significantly $(P \leq 0.001)$ associated with the most serious complications in PE cases such as HELP and IUFD (Table-4).

Table-2: The relationship between rs1570360 genotyping and the severity of pre-eclampsia

\begin{tabular}{|c|c|c|c|c|c|}
\hline \multirow[t]{2}{*}{ Genotyping } & \multicolumn{2}{|c|}{ Pre-eclampsia in cases } & \multirow{2}{*}{$\begin{array}{l}\text { Total } \\
(\mathrm{n}=100) \\
\mathrm{N}(\%)\end{array}$} & \multirow{2}{*}{$\begin{array}{l}\text { Test of significance } \\
\qquad\left(\chi^{2}\right)\end{array}$} & \multirow[t]{2}{*}{$P$ value } \\
\hline & $\begin{array}{l}\text { Mild } \\
(\mathrm{n}=54) \\
\mathrm{N}(\%)\end{array}$ & $\begin{array}{c}\text { Severe } \\
(\mathrm{n}=46) \\
\mathrm{N}(\%)\end{array}$ & & & \\
\hline GG (wild type) & $38(70.4)$ & $4(8.7)$ & $42(42)$ & \multirow{3}{*}{43.256} & \multirow{3}{*}{$<0.001 * *$} \\
\hline AA & $8(14.8)$ & $34(73.9)$ & $42(42)$ & & \\
\hline $\mathrm{AG}$ & $8(14.8)$ & $8(17.4)$ & $16(16)$ & & \\
\hline
\end{tabular}


Table-3: Binary logistic regression of rs1570360 genotyping and the severity of pre-eclampsia

\begin{tabular}{|l|c|c|c|c|c|}
\hline \multirow{2}{*}{ Genotyping } & \multicolumn{2}{|c|}{ Pre-eclampsia } & Odds ratio & 95\% CI (lower-upper) & P value \\
\cline { 2 - 6 } & $\begin{array}{l}\text { Mild } \\
(\mathrm{n}=54) \\
\mathrm{N}(\%)\end{array}$ & $\begin{array}{c}\text { Severe } \\
(\mathrm{n}=46)\end{array}$ & $\mathrm{N}(\%)$ & & \\
\hline AA & $8(14.8)$ & $34(73.9)$ & 40.375 & $11.155-146.135$ & $<\mathbf{0 . 0 0 1} * *$ \\
\hline AG & $8(14.8)$ & $8(17.4)$ & 9.5 & $2.292-39.378$ & $\mathbf{0 . 0 0 2} *$ \\
\hline GG (wild type) & $38(70.4)$ & $4(8.7)$ & & - & \\
\hline \multicolumn{7}{|c|}{$* *$ highly significant } \\
$* P$ value $\leq 0.05:$ Significant
\end{tabular}

Table-4: Relation between the polymorphism homozygocity and the occurrence of most serious complications in PE cases

\begin{tabular}{|l|c|c|c|c|l|}
\hline \multirow{2}{*}{ Complications } & \multicolumn{2}{|c|}{ AA } & Total & Test of significance $\left(\chi^{2}\right)$ & $P$ value \\
\cline { 2 - 4 } & $\begin{array}{c}\text { Present } \\
\text { N (\%) }\end{array}$ & $\begin{array}{c}\text { Absent } \\
\text { N }(\%)\end{array}$ & & & \\
\hline Eclampsia & $8(22.2)$ & - & $8(8.9)$ & & \\
\hline IUFD & $4(11.1)$ & - & $4(4.4)$ & \multirow{3}{*}{33.75} & $<0.001 * *$ \\
\hline Eclampsia+IUFD & $2(5.6)$ & - & $2(2.2)$ & \\
\hline HELP & $4(11.1)$ & - & $4(4.4)$ & & \\
\hline No complications & $18(50)$ & $54(100)$ & $72(80)$ & & \\
\hline \multicolumn{7}{|c|}{$* *:$ highly significant } \\
\hline
\end{tabular}

\section{DISCUSSION}

Pre-eclampsia (PE), a human-pregnancyrelated disease described as the appearance of hypertension and significant proteinuria in a previously healthy pregnant woman after the 20th week of gestation. It occurs in about $2-8 \%$ of pregnancies [15]. Despite its prevalence and severity, there is no definite theory explaining PE's pathophysiology. Different theories includes a combination of immunological, inflammatory, dietary and genetic factors leading to the failure of normal trophoblastic invasion and uterine spiral artery remodeling [16].

The cause of PE remains unclear but there is increasing evidence that an imbalance between the VEGF family and potential anti-angiogenic factors is closely linked to PE pathogenesis. A highly coordinated system ensures that the placenta and fetus receive adequate blood supply needed for proper oxygen and nutrient delivery during a regular and healthy pregnancy. Developing evidence indicates that VEGF is elevated in PE and associates with disease severity and complications [17]. Unlike some reports have found decreased VEGF rates in PE-women's sera [18].

As a member of the VEGF family, VEGF $A$ is a significant angiogenic factor and potent regulator of the proliferation of endothelial cells [19]. There are many popular single nucleotide polymorphisms (SNPs) in the VEGF gene, including positions + 936 (rs3025039), -634 (rs2010963), -1154 (rs1570360), and -2578 (rs699947), which may alter the gene expression and affect the risk of developing diseases defined by deranged angiogenesis [20]. Hence, abnormal angiogenesis and related fetoplacental vascular dysfunction are considered essential steps in the development of PE [21]. Thus, in recent years, one field of intensive work has concentrated on the VEGF signaling pathway in the progression of PE, which is essential to maintain proper endothelial cell function and health. Case-control studies have recently shown associations between polymorphisms of the VEGF genes and PE [22].

In the present study, the associations between the polymorphisms in VEGF genes (rs1570360) and PE were investigated which might play a role in this disease. To the best of our knowledge, this is the first analysis to evaluate the relationship between SNPs in the VEGF gene and the risk of PE in Egyptians.

The VEGF is a multifunctional cytokine that plays a key role in the in vivo angiogenesis and placental development [23]. The VEGF gene has many polymorphisms, and several polymorphisms are associated with the development of proteins [24]. In addition, there was a lack of association of the genotypes of VEGFA SNPs with PE, regardless of the genetic model used. However, among seven-locus studied, results suggest that VEGFA haplotypes, more so than individual SNPs, play a role in PE pathogenesis in Tunisian women [25].

The VEGFA gene rs1570360 (-1154G/A), in the promoter region, was reported to modulate VEGF [26]. Herein, the rs1570360 (-1154G/A) polymorphisms had no association with PE risk in all examined patients. However, there was a relation between genotyping and the severity of pre-eclampsia. A strong association was found between AA and severe cases even with the development of complications in these cases. 


\section{CONCLUSION}

Our results suggested that VEGFA gene rs1570360 or (-1154G/A) polymorphism had no association with PE risk in all examined patients. In order to warrant and confirm the associations between VEGFA gene polymorphisms and PE risk, further studies are therefore required. However, AA genotype was found in each severe case associated with serious complications of PE disorder.

\section{REFERENCES}

1. Stone, P., Cook, D., Hutton, J., Purdie, G., Murray, H., \& Harcourt, L. (1995). Measurements of blood pressure, oedema and protein-uria in a pregnant population of New Zealand. Australian and New Zealand Journal of Obstetrics and Gynaecology, 7, 35-32.

2. Report of the National High Blood Pressure Education Program Working Group on High Blood Pressure in Pregnancy. (2000). American journal of obstetrics and gynecology, 183(1), S1-S22.

3. Caritis, S., Sibai, B., Hauth, J., Lindheimer, M. D., Klebanoff, M., Thom, E., VanDorsten, P., Landon, M., Paul, R., Miodovnik, M., Meis, P., \& Thurnau, G. (1998). Low-dose aspirin to prevent preeclampsia in women at high risk. National Institute of Child Health and Human Development Network of Maternal-Fetal Medicine Units. The New England journal of medicine, 338(11), 701-705.

4. Fisher, K. A., Luger, A., Spargo, B. H., \& Lindheimer, M. D. (1981). Hypertension in pregnancy: clinical-pathological correlations and remote prognosis. Medicine, 60(4), 267-276.

5. Duckitt, K., \& Harrington, D. (2005). Risk factors for pre-eclampsia at antenatal booking: systematic review of controlled studies. BMJ (Clinical research ed.), 330(7491), 565.

6. Carr, D. B., Epplein, M., Johnson, C. O., Easterling, T. R., \& Critchlow, C. W. (2005). A sister's risk: family history as a predictor of preeclampsia. American journal of obstetrics and gynecology, 193(3 Pt 2), 965-972.

7. Sibai, B. M. (2003). Diagnosis and management of gestational hypertension and preeclampsia. Obstetrics and gynecology, 102(1), 181-192.

8. Abalos, E., Duley, L., Steyn, D. W., \& Gialdini, C. (2018). Antihypertensive drug therapy for mild to moderate hypertension during pregnancy. The Cochrane database of systematic reviews, 10(10), CD002252.

9. Publications Committee, Society for Maternal-Fetal Medicine, \& Sibai, B. M. (2011). Evaluation and management of severe preeclampsia before 34 weeks' gestation. American journal of obstetrics and gynecology, 205(3), 191-198.

10. El-Garawani, I., Hassab El-Nabi, S., Gadallah, M., \& Abdelsameea, E. (2020). Association between IFN- $\lambda$ 3 Gene Polymorphisms and Outcome of Treatment with Direct Acting Antivirals in Chronic HCVInfected Egyptian Patients. Immunological investigations, $1-11$.
11. El-Nabi, S. H., Sayed, S., Abd-Elhafez, M. A., Elfiky, M., Abdel Moneim, A. E., \& El-Garawani, I. (2020). Arg753Gln Polymorphisms in the Toll-Like Receptor 2 Gene are Associated with Cytomegalovirus Infection in Egyptian Bone Marrow Recipients. Endocrine, metabolic \& immune disorders drug targets, 20(4), 619-624.

12. El-Garawani, I. (2015). Ameliorative effect of Cymbopogon citratus extract on cisplatin-induced genotoxicity in human leukocytes. Journal of Bioscience and Applied Research, 1(6):304-310.

13. Aljanabi, S. M., \& Martinez, I. (1997). Universal and rapid salt-extraction of high quality genomic DNA for PCR-based techniques. Nucleic acids research, 25(22), 4692-4693.

14. El-Garawani, I., \& Hassab El-Nabi, S. (2016). Increased sensitivity of apoptosis detection using direct DNA staining method and integration of acridine orange as an alternative safer fluorescent dye in agarose gel electrophoresis and micronucleus test. Canadian Journal of Pure and Applied Sciences, 102: 3865-3871.

15. Ghulmiyyah, L., \& Sibai, B. (2012). Maternal mortality from preeclampsia/eclampsia. Seminars in perinatology, 36(1), 56-59.

16. Roberts J. M. (2014). Pathophysiology of ischemic placental disease. Seminars in perinatology, 38(3), $139-145$.

17. Ong, S., Lash, G., \& Baker, P. N. (2000). Angiogenesis and placental growth in normal and compromised pregnancies. Bailliere's best practice \& research. Clinical obstetrics \& gynaecology, 14(6), 969-980.

18. Brownbill, P., Mills, T. A., Soydemir, D. F., \& Sibley, C. P. (2008). Vasoactivity to and endogenous release of vascular endothelial growth factor in the in vitro perfused human placental lobule from pregnancies complicated by preeclampsia. Placenta, 29(11), 950-955.

19. Atis, A., Oruc, O., Aydin, Y., Cetincelik, U., \& Goker, N. (2012). Vascular endothelial growth factor gene $+813 \mathrm{CC}$ polymorphism of foetus is associated with preterm labour but not with pre-eclampsia in Turkish pregnant women. International journal of immunogenetics, 39(3), 241-246.

20. Andraweera, P. H., Dekker, G. A., Dissanayake, V. H., Bianco-Miotto, T., Jayasekara, R. W., \& Roberts, C. T. (2013). Vascular endothelial growth factor family gene polymorphisms in preeclampsia in Sinhalese women in Sri-Lanka. The journal of maternal-fetal \& neonatal medicine : the official journal of the European Association of Perinatal Medicine, the Federation of Asia and Oceania Perinatal Societies, the International Society of Perinatal Obstetricians, 26(5), 532-536.

21. Nikuei, P., Malekzadeh, K., Rajaei, M., Nejatizadeh, A., \& Ghasemi, N. (2015). The imbalance in expression of angiogenic and anti-angiogenic factors as candidate predictive biomarker in preeclampsia. Iranian journal of reproductive medicine, 13(5), 251-262.

22. Cheng, D., Hao, Y., Zhou, W., \& Ma, Y. (2013). Vascular endothelial growth factor +936C/T, - 
634G/C, -2578C/A, and -1154G/A polymorphisms with risk of preeclampsia: a meta-analysis. PloS one, $8(11)$, e78173.

23. Weel, I. C., Baergen, R. N., Romão-Veiga, M., Borges, V. T., Ribeiro, V. R., Witkin, S. S., Bannwart-Castro, C., Peraçoli, J. C., De Oliveira, L., \& Peraçoli, M. T. (2016). Association between Placental Lesions, Cytokines and Angiogenic Factors in Pregnant Women with Preeclampsia. PloS one, 11(6), e0157584.

24. Ferrara, N. (2001). Role of vascular endothelial growth factor in regulation of physiological angiogenesis. American journal of physiology. Cell physiology, 280(6), C1358-C1366.
25. Ben Ali Gannoun, M., Al-Madhi, S. A., Zitouni, H., Raguema, N., Meddeb, S., Hachena, B. A. F., Mahjoub, T., \& Almawi, W. Y. (2017). Vascular endothelial growth factor single nucleotide polymorphisms and haplotypes in pre-eclampsia: A case-control study. Cytokine, 97, 175-180.

26. Salimi, S., Yaghmaei, M., Tabatabaei, E., Mokhtari, M., \& Naghavi, A. (2015). Vascular endothelial growth factor (VEGF)-634G/C polymorphism was associated with severe pre-eclampsia and lower serum VEGF level. The journal of obstetrics and gynaecology research, 41(12), 1877-1883. 